\title{
APPLICATION OF BAYESIAN TECHNIQUE FOR PARAMETER ESTIMATION IN A FERMENTATIVE PROCESS
}

\author{
C. A. Azevedo ${ }^{a}$, \\ C. T. Falcón ${ }^{\mathrm{a}}$, \\ and D. C. Estumano ${ }^{\mathrm{b}}$ \\ ${ }^{a}$ Universidade Federal do Pará \\ Instituto de Tecnologia \\ Rua Augusto Corrêa, 01 \\ Campus Universitário do Guamá \\ CEP 66.075-110, Belém, Pará, Brasil \\ carla_arnaud@outlook.com \\ cindytorres9125@gmail.com

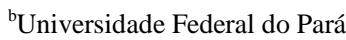 \\ Instituto de Ciências Biológicas \\ Rua Augusto Corrêa, 01 \\ Campus Universitário do Guamá \\ CEP 66.075-110, Belém, Pará, Brasil \\ dcestumano@ufpa.br \\ ABSTRACT \\ In the current world scenario, there has been noted an increase of researches \\ on biofuel production, more specifically bioethanol, produced from \\ biomass, in order to obtain more information to analyze, understand and \\ optimize this fermentative process. The modelling process, which include \\ the determination of a kinetic model and its respective parameters, is a \\ fundamental step in defining operating strategies and understand how the \\ experimental conditions can affect the optimal system operating conditions. \\ The present work employs a bayesian technique to estimate the parameters \\ of a classical kinectic model used by Silva and collaborators (2016), \\ because, unlike the classical techniques, it is possible to take into account \\ the uncertainty of the measurements and the prior knowledge of the \\ parameters can be accounted for in probabilistic terms. In this context, by \\ using simulated measurements, for the parameters estimation it is propose a \\ sensitivity analysis of the parameters model to define the most relevant ones \\ to be estimate and the use of the Monte Carlo Markov Chain method \\ through the Metropolis-Hastings algorithm, evaluating the influence of four \\ types of priori probability distribution of data set: uniform, gaussian, log- \\ normal and Rayleigh. The obtained results showed that the sensibility \\ analysis is an important step on parameter estimation and algorithm used \\ was satisfactory in estimating the parameters of the kinectic model used, \\ demonstrating the possibility of using it as a tool for time and cost reduction \\ in experimental tests. \\ Received: February 18, 2020 \\ Revised: March 18, 2020 \\ Accepted: April 18, 2020 \\ Keywords: fermentative process; metropolis-hastings; markov chain monte \\ carlo; parameter estimation; priori probability distribution
}

\section{NOMENCLATURE}

a

$\mathrm{b}$

C

C

$\mathrm{C}_{\mathrm{S}}$

K

k

$\mathrm{K}_{1}$

$\mathrm{K}_{\mathrm{S}}$

P

$P_{i}$

$\mathrm{P}_{\text {ref }}$

$\mathrm{S}$

$\mathrm{S}_{1}$

u

W

X

$\mathrm{X}$

$X_{i, j}$

$\mathrm{Xp}_{\mathrm{i}, \mathrm{j}}$

$\mathrm{Y}_{\mathrm{X} / \mathrm{P}}$

$\mathrm{Y}_{\mathrm{X} / \mathrm{S}}$

ethanol, g.L ${ }^{-1}$

parameter

sucrose, g. $L^{-1}$

glucose, g. $\mathrm{L}^{-1}$

search step

biomass, g. $\mathrm{L}^{-1}$ uniform distribution parameter

uniform distribution parameter

measurements from direct model solution

Rayleigh distribution parameter

simulated measurements

kinetic constant, $\mathrm{h}^{-1}$

random variable with Gaussian distribution

from Metropolis-Hastings algorithm

kinetic constant, $\mathrm{h}^{-1}$

saturation constant, g. $\mathrm{L}^{-1}$

parameter reference

random number with Uniform distribution

random variable from the probability

distributions

sensitivity coefficient

reduced sensitivity coefficients

substrate conversion factor for product

substrate conversion factor for biomass

\section{Greek symbols}

$\varepsilon \quad$ perturbation

$\lambda$ random variable with Gaussian distribution from simulated measurements

$\mu \quad$ specific reproduction velocity of microorganisms, $\mathrm{h}^{-1}$

$\mu_{\text {máx }} \quad$ maximum specific growth velocity

$\boldsymbol{\pi}(\mathbf{C})$ probability distribution of the data.

$\boldsymbol{\pi}(\mathbf{C} \mid \mathbf{P})$ likelihood function

$\boldsymbol{\pi}(\mathbf{P}) \quad$ priori probability distribution

$\boldsymbol{\pi}(\mathbf{P} \mid \mathbf{C})$ posteriori probability distribution

$\sigma \quad$ standard deviation

$\varphi \quad$ Metropolis test

\section{INTRODUCTION}

In Brazil, a tropical country, there is great potential for the use of biomass for ethanol production, as this is an attractive and sustainable energy source when compared to the fossil fuel energy matrix, whose burning produces large amounts of greenhouse gases and contributes significantly for global climate changes (Goldemberg et al., 2004; Gnansounou and Dauriat, 2005).

In this way there has been an intensification in 
researches on biofuel production, more specifically bioethanol (ethanol from biomass) in order to analyze, understand and optimize this fermentation process (Akgul et al., 2010; Corsano et al., 2011; Nitsos et al., 2013). The modelling process is a fundamental step in defining operating strategies, given that most of the problems reported about this process are the influence of experimental conditions on response variables, such as yield, productivity and conversion, and how they affect the optimal system operating conditions (Rivera et al., 2006).

The determination of a kinetic model and its respective parameters are considered the most relevant stage in the study of modeling and optimizing a fermentation process, however some of these parameters cannot be obtained directly experimentally. Hence, some inferences are made with information about the reactants and products concentrations of the fermentative process. The estimation of such parameters can be performed by various techniques, such as the least squares, conjugate gradient or particle swarm, which was used in the reference article. However, these methods, unlike the bayesian techniques, do not take into account the uncertainty of the measurements and also do not allow prior knowledge of the parameters to be accounted for in probabilistic terms.

In this scenario the present work aims to present the application of the Markov Chain Bayesian Monte Carlo technique (MCMC) to estimate kinetic parameters of a classical kinectic model employed by using simulated measurements to describe the experimental data obtained by the authors of the reference article "Modelling and parameter estimation of ethanol production in a batch reactor by Saccharomyces cerevisiae" (Silva et al., 2016) by analyzing the sensitivity coefficients of the parameters and evaluating the influence of prior probability distribution information on parameter estimation.

\section{MATHEMATICAL MODEL}

To describe the dynamics of the concentration of the state variables, in this case biomass (X), sucrose $(\mathrm{S})$, glucose $\left(\mathrm{S}_{1}\right)$ and ethanol $(\mathrm{P})$, it was used an classical model, considering that the fermentation process occurred in batch under perfect mixing conditions and a sufficient stirring speed to provide a uniform and adequate mass transfer and substrate availability:

$$
\begin{gathered}
\frac{\mathrm{dX}}{\mathrm{dt}}=\mu . \mathrm{X} \\
\frac{\mathrm{dS}}{\mathrm{dt}}=-\frac{\mu \cdot \mathrm{X}}{\mathrm{Y}_{\mathrm{X} / \mathrm{S}}} \\
\frac{\mathrm{dS}}{\mathrm{dt}}=\mathrm{K}_{1} \cdot \mathrm{S}-\mathrm{K} \cdot \mathrm{S}_{1}
\end{gathered}
$$

$$
\frac{\mathrm{dP}}{\mathrm{dt}}=\frac{\mu \cdot \mathrm{X}}{\mathrm{Y}_{\mathrm{X} / \mathrm{P}}}
$$

This model is composed by the differential equations presented in Eqs. (1) - (4). In Eq. (3) was proposed based on the glucose reaction rate in an alcoholic fermentation system. The term $\mu\left(\mathrm{h}^{-1}\right)$ is the specific reproduction velocity of microorganisms, defined by the Monod Equation:

$$
\mu=\frac{\mu_{\text {máx }} \cdot S}{K_{S}+S}
$$

The $Y_{X / S}$ and $Y_{X / P}$ terms corresponds to the substrate conversion factors for biomass and product, respectively; $K_{1}\left(\mathrm{~h}^{-1}\right)$ and $K\left(\mathrm{~h}^{-1}\right)$ are the reaction kinetic constants, $\mu_{\text {máx }}$ is related to the maximum specific growth velocity and $\mathrm{K}_{\mathrm{S}}\left(\mathrm{g} . \mathrm{L}^{-1}\right)$, showed in Eq. (5), represents the saturation constant.

\section{PARAMETER SENSIBILITY ANALYSIS}

In order to obtain accuracy and precision in parameter estimation, it is possible to analyze the sensitivity coefficients, which is used to determine the magnitude of the parameter and to evaluate the existence of linear dependence between the parameters (Beck et al., 1985) as follows:

$$
\mathrm{X}_{\mathrm{i}, \mathrm{j}}=\frac{\partial \mathrm{C}_{\mathrm{i}}}{\partial \mathrm{P}_{\mathrm{j}}}
$$

For problems involving parameters with different magnitude orders, difficulties in comparing and identifying the linear dependence of the parameters may occur when using Eq. (6), This problem can be minimized by analyzing the reduced sensitivity coefficients:

$$
\mathrm{X}_{\mathrm{P}_{\mathrm{i}, \mathrm{j}}}=\mathrm{P}_{\mathrm{j}} \frac{\partial \mathrm{C}_{\mathrm{i}}}{\partial \mathrm{P}_{\mathrm{j}}}
$$

As defined in Eq. (7), the sensitivity of the concentration $\mathrm{Ci}$ can be estimated in relation to the perturbations imposed on the corresponding parameters, represented by $\mathrm{Pj}$. The smaller the magnitude of the coefficient, the harder it is to estimate the parameter in relation to the corresponding state variable (Naveira Cotta, 2009). In cases where an analytical solution is not available, the advanced or centered finite difference method is used. The centered finite difference method is considered more accurate (Ozisik and Orlande, 2000) and was applied in this work:

$\mathrm{X}_{\mathrm{P}_{\mathrm{i}, \mathrm{j}}}=$ 


$$
=\frac{\mathrm{C}_{\mathrm{i}}\left(\mathrm{P}_{1}, \mathrm{P}_{2}, \ldots \mathrm{P}_{\mathrm{j}}+\varepsilon \mathrm{P}_{\mathrm{j}}, \ldots \mathrm{P}_{\mathrm{NP}}\right)-\mathrm{C}_{\mathrm{i}}\left(\mathrm{P}_{1}, \mathrm{P}_{2}, \ldots \mathrm{P}_{\mathrm{j}}-\varepsilon \mathrm{P}_{\mathrm{j}}, \ldots \mathrm{P}_{\mathrm{NP}}\right)}{2 \varepsilon}
$$

The perturbation value $\varepsilon$, presented in Eq. (8), should be carefully chosen to avoid numerical or approximation errors.

\section{BAYESIAN INFERENCE}

The Bayesian inference, through the theory of statistical inversion, aims to extract all information and uncertainties about the state variables of the studied model, in order to estimates parameters and state variables from observable data in a confidence interval. (Gianola and Fernardo, 1986; Resende, 1999). Thus, all variables are treated as random and the solution of an inverse problem is obtained from the probability distribution of the amount of interest when all available information has been incorporated into the model. This distribution is called posteriori probability distribution (Kaipio and Somersalo, 2004).

The Bayesian analysis is based on the probability distribution of the parameters using all available information about the studied phenomenon, defined as priori probability distribution, $\boldsymbol{\pi}(\mathbf{P})$. After observing the sample data, it is possible to construct the posteriori probability distribution, $\boldsymbol{\pi}(\mathbf{P} \mid \mathbf{C})$. In this way, the Bayes Theorem indicates that:

$$
\begin{aligned}
& \pi(\mathbf{P} \mid \mathbf{C})=\frac{\pi(\mathbf{P}) \pi(\mathbf{C} \mid \mathbf{P})}{\pi(\mathbf{C})} \\
& \pi(\mathbf{P} \mid \mathbf{C}) \propto \pi(\mathbf{P}) \pi(\mathbf{C} \mid \mathbf{P})
\end{aligned}
$$

In Eq. (9), the $\mathbf{P}$ and $\mathbf{C}$ terms indicates the observed parameter and experimental data, respectively. The term $\boldsymbol{\pi}(\mathbf{C} \mid \mathbf{P})$ is the likelihood function and denotes the parameter information from the observed data for each possible value of $\mathrm{P}$ (sample distribution), while the term $\boldsymbol{\pi}(\mathbf{C})$ represents the probability distribution of the data. The posteriori probability distribution $\boldsymbol{\pi ( P | C )}$ can be written according to Eq. (10).

It is possible to calculate the likelihood function (Ozisik and Orlande, 2000) as follows:

$$
\begin{aligned}
& \pi(\mathbf{C} \mid \mathbf{P})=(2 \pi)^{-\frac{1}{2}}|\mathrm{~W}|^{\frac{1}{2}} \\
& \exp \left\{-\frac{1}{2}\left[\mathrm{C}^{\text {med }}-\mathrm{C}^{\text {pred }}(\mathbf{P})\right]^{\mathrm{T}} \mathrm{W}^{-1}\left[\mathrm{C}^{\text {med }}-\mathrm{C}^{\text {pred }}(\mathbf{P})\right]\right\}
\end{aligned}
$$

In Eq. (11), were consider that the errors of the measurements are gaussian, uncorrelated, additive and independent (Beck and Arnold, 1977; Beck et al., 1985; Beck, 1979). The posteriori probability distribution contains the estimates of the parameter of interest, which can be summarized through punctual measures such as median, mode and mean (Gamerman and Migon, 1993).

\section{Markov Chain Monte Carlo Method}

The Markov Chain Monte Carlo (MCMC) method can be used for sampling from a priori probability distribution and inverse problem characterization (Kaipio and Somersalo, 2005). A Markov chain is a type of stochastic process where, given current behavior, the probability of any future process behavior is not altered by additional knowledge about its past behavior (Gamerman and Lopes, 2006).

In order to obtain only one equilibrium distribution, the MCMC methods require the Markov chain to be homogeneous, irreducible, and nonperiodic (Ehlers, 2011). The central idea of the MCMC is that as the number of iterations increases, the initial points (burn-in period) are forgotten and the convergence of the Markov chain to an equilibrium distribution (a posteriori probability distribution) occurs gradually and satisfactorily to the distribution of interest. The generating of a sequence with many simulated values are used to interpret the characteristics of the a posteriori probability distribution (Gamerman and Lopes, 2006).

The number of iterations required for Markov chain convergence can be determined by several methods described in the literature (Heidelberger and Welch, 1983; Geweke et al., 1994; Raftery and Lewis, 1991; Gelfand and Smith, 1990).

In this work the acceptance-rejection Metropolis-Hastings algorithm were used and it works by generating a posteriori joint distribution, $\boldsymbol{\pi}(\mathbf{P 1}, \mathbf{P 2}$...|C) from the existing conditional distributions (Metropolis and Ulam, 1949; Hastings, 1970), in which a given value is generated from a transition kernel and can be accepted with a given probability.

\section{NUMERICAL METHODOLOGY}

\section{Simulated Measurements}

To represent the experimental scenario, simulated measurements $\left(C_{S}\right)$ were generated with a defined uncertainty level regarding the exact solution (2.5\% for all state variables):

$$
C_{S}=C+\sigma \lambda
$$

In Eq. (12), $C$ is obtained in the solution of the direct problem, $\sigma$ is the standard deviation of the measurements and $\lambda$ is the random variable with Gaussian distribution N $(0,1)$.

\section{Priori Probability Distribution}

Some case studies were carried out by 
employing different priori information of the parameters in order to verify its influence on the estimation. Four types of probability distributions were used as priori information of the unknown parameters of the model, so that each model the uncertainties and describe the phenomena in different ways. The probability distributions used, considering a continuous random variable $\mathrm{x}$ :

$$
\begin{gathered}
\mathrm{f}(\mathrm{x})= \begin{cases}\frac{1}{\mathrm{~b}-\mathrm{a}} & \mathrm{a}<\mathrm{x}<\mathrm{b} \\
0 & \text { GAUSSIAN }\end{cases} \\
\mathrm{f}(\mathrm{x})=\frac{1}{\sqrt{2 \pi} \sigma} \exp \left[-\frac{1}{2}\left(\frac{\mathrm{x}-\mu}{\sigma}\right)^{2}\right] \\
\mathrm{f}(\mathrm{x})=\frac{1}{\mathrm{x} \sigma \sqrt{2 \pi}} \exp \left[-\frac{1}{2}\left(\frac{\ln (\mathrm{x})-\mu}{\sigma}\right)^{2}\right] \\
\mathrm{f}(\mathrm{x})=\frac{\mathrm{x}}{\mathrm{c}^{2}} \exp \left[-\frac{1}{2}\left(\frac{\mathrm{x}}{\mathrm{c}}\right)^{2}\right]
\end{gathered}
$$

In Eqs. (13) to (16), the $\mathrm{f}(\mathrm{x})$ represents the priori probability distribution and $\mathrm{x}$ is the model parameter vector.

The values defined for the distribution parameters in each case studied are shown in Table 1.

Table 1. Probability distribution parameters.

\begin{tabular}{|c|c|cc|}
\hline Case & $\begin{array}{c}\text { Probability } \\
\text { Distribution }\end{array}$ & \multicolumn{2}{|c|}{ Parameters } \\
\hline 1 & Uniform & $\mathrm{a}=0 * \mathrm{P}_{\text {ref }}$ & $\mathrm{b}=3.0 * \mathrm{P}_{\text {ref }}$ \\
\hline 2 & Gaussian & $\mu=\mathrm{P}_{\text {ref }}$ & $\sigma=0.2 * \mathrm{P}_{\text {ref }}$ \\
\hline 3 & Log-normal & $\mu=\mathrm{P}_{\text {ref }}$ & $\sigma=0.3 * \mathrm{P}_{\text {ref }}$ \\
\hline 4 & Rayleigh & \multicolumn{2}{|c|}{$\mathrm{c}=0.25$} \\
\hline
\end{tabular}

\section{Metropolis-Hastings Algorithm}

This Metropolis-Hastings algorithm can be generalized as follows (Lee, 2004):

1. Initialize the Markov chain iteration counter $(\mathrm{i}=0)$ and arbitrate an initial value $\mathrm{P}^{(0)}$;

2. Generate a candidate value $\mathrm{P}^{\prime}$ from the proposed distribution $\mathrm{q}\left(\mathrm{P}^{\prime} \mid \mathrm{P}^{\mathrm{i}}\right)$, where $\mathrm{k}$ is a variable $\mathrm{N}(0,1)$ and $\mathrm{w}$ is the search step;

$$
\mathrm{P}^{\prime}=\mathrm{P}^{(\mathrm{i}-1)}(1+\mathrm{wk})
$$

3. Calculate the probability of acceptance $(\varphi)$ of the candidate parameter by the Metropolis test;

$$
\varphi=\min \left[1, \frac{\pi\left(\mathrm{P}^{\prime} \mid \mathrm{Y}\right) \mathrm{q}\left(\mathrm{P}^{\prime}, \mathrm{P}^{(\mathrm{i}-1)}\right)}{\pi\left(\mathrm{P}^{(\mathrm{i}-1)} \mid \mathrm{Y}\right) \mathrm{q}\left(\mathrm{P}^{(\mathrm{i}-1)}, \mathrm{P}^{\prime}\right)}\right]
$$

4. Generate a random number $\mathrm{u}$ with uniform distribution, $\mathrm{u} \sim \mathrm{U}(0,1)$;

5. If $\mathrm{u} \leq \varphi$, then the new value is accepted and $\mathrm{P}^{(\mathrm{i})}=\mathrm{P}^{\prime}$. Otherwise, reject it and make $\mathrm{P}^{(\mathrm{i})}=\mathrm{P}^{(\mathrm{i}-1)}$;

6 . Increase the counter from $\mathrm{i}$ to $\mathrm{i}+1$ and return to step 2 .

By using this algorithm, it is possible to obtain a sequence where the samples generated after the burnin period correspond to the posteriori probability distribution of the parameters. In this paper, were made inferences about this by the mean and the intervals of credibility (Kaipio and Somersalo, 2005).

\section{RESULTS AND DISCUSSION}

The present work used as reference the data obtained experimentally by Silva et al. (2016) and Table 2 presents the reference values of the parameters and the initial conditions of each state variable for the employed model.

Initially, the direct model was solved, the analysis of the sensitivity coefficients of the model parameters was performed, followed by the parameter estimation through the algorithm, evaluating the influence of the priori probability distribution on the parameter estimation.

Table 2. Parameter reference values and initial conditions of the state variables.

\begin{tabular}{|c|c|}
\hline State Variable & Initial Condition (g/L) \\
\hline $\mathrm{X}$ & 4.7 \\
\hline $\mathrm{S}$ & 94.0 \\
\hline $\mathrm{S}_{1}$ & 39.0 \\
\hline $\mathrm{P}$ & 0.0 \\
\hline Parameter & Reference Value \\
\hline$\mu_{\text {máx }}$ & 0.1155 \\
\hline $\mathrm{K}$ & 0.4738 \\
\hline $\mathrm{K}_{1}$ & 0.8934 \\
\hline $\mathrm{K}_{\mathrm{S}}$ & 24.3752 \\
\hline $\mathrm{Y}_{\mathrm{X} / \mathrm{S}}$ & 0.0242 \\
\hline $\mathrm{Y}_{\mathrm{X} / \mathrm{P}}$ & 0.0451 \\
\hline
\end{tabular}

From the information provided by the reference article, the direct model was solved and the dynamics graph of the state variables of the model was constructed, as shown in Fig. 1.

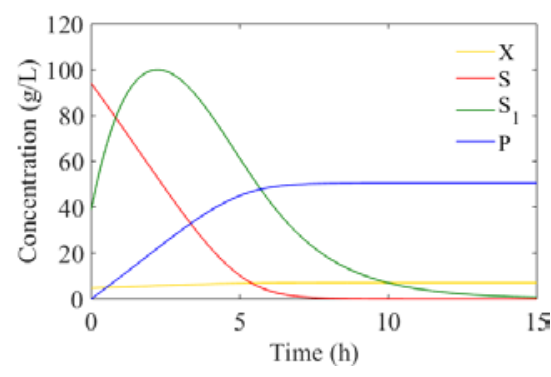

Figure 1. Dynamic of state variables. 
It can be observed that the solution obtained in the present work is in excellent agreement with the experimental data obtained by Silva et al. (2016). The dynamics of biomass, sucrose, glucose and ethanol coincide with the behavior predicted in the literature about fermentation processes.

When it comes to the sensitivity analysis of the parameters, the advantage of doing this analysis before estimating the parameters is the possibility of obtain a more detailed understanding of their influence on state variables, especially in problems with a large number of parameters, since the sensitivity matrix evaluation is a process that takes time and computational cost. The sensitivity coefficients of the model parameters in relation to the state variables were evaluated, as presented in Fig. 2.
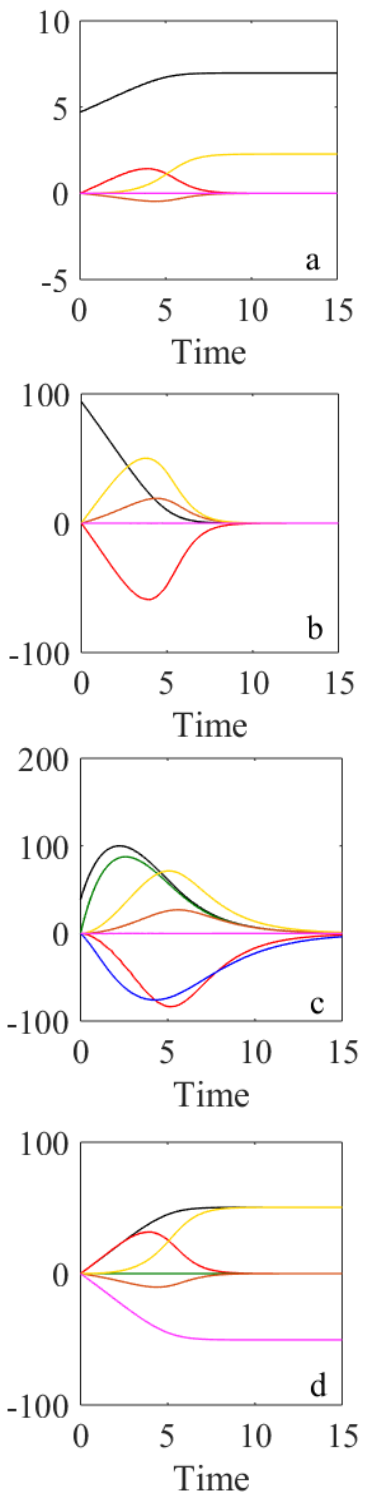

Figure 2. Sensibility analysis of parameters for a) biomass, b) sucrose, c) glucose and d) ethanol, where state variables (black), $\mu_{\text {máx }}$ (red) $\mathrm{K}$ (blue), $\mathrm{K}_{1}$ (green), $\mathrm{K}_{\mathrm{S}}$ (brown), $\mathrm{Y}_{\mathrm{X} / \mathrm{S}}$ (yellow) and $\mathrm{Y}_{\mathrm{X} / \mathrm{P}}$ (pink).
For biomass and sucrose, only three of the six parameters have significant magnitude, being $\mu_{\max }$, $\mathrm{Y}_{\mathrm{X} / \mathrm{S}}$ and $\mathrm{K}_{\mathrm{S}}$. Those parameters showed themselves as linearly independent in the transient period of the graph, which may contribute to a better parameter estimation. For glucose, which is intermediate of the reaction, all parameters except $\mathrm{Y}_{\mathrm{X} / \mathrm{P}}$ had a significant magnitude, but only $\mathrm{K}_{\mathrm{S}}$ was linearly independent. For ethanol, parameters $\mathrm{K}$ and $\mathrm{K}_{1}$ had a minimum magnitude, indicating that they are not relevant for this state variable. On the other hand, the parameters that showed high sensitivity and considerable magnitude were presented as linearly independent, indicating a good fit of the model to the experimental data. Thus, it can be concluded that the parameters $\mu_{\max }, K_{S}$ and $Y_{X / S}$ are the parameters that, even under small perturbations, have significant influence on the state variables of the studied model.

The cases studied covered four types of probability distributions. The Fig. 3 presents the estimation of the parameters from the convergence of Markov chains for all studied cases.
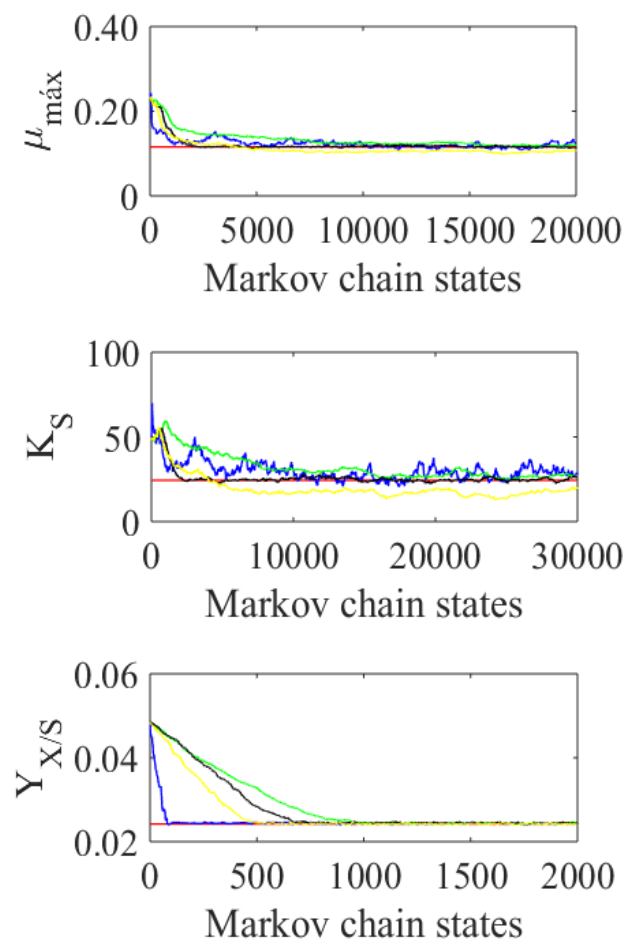

Figure 3. Markov chain evolution for $\mu_{\text {máx }}, K_{\mathrm{S}}$ and $\mathrm{Y}_{\mathrm{X} / \mathrm{S}}$, where reference value (red), uniform (blue), gaussian (green), log-normal (black) and Rayleigh (yellow).

Looking at Fig. 3, it can be noted that all priori distributions converged to a value relatively close to the parameter reference value, with Log-normal being the closest. The priori of the uniform type is considered non-informative and therefore the parameters to be estimated are put as equiprobable. On the other hand, the Gaussian, Log-normal and 
Rayleigh distributions may be employed in cases where there is a better understanding of the behavior of the parameters, usually dispersed around a mean that representing the parameter reference value.

The Table 3 has the results of the posteriori probability distribution information of the estimated parameters. For all parameters, the initial values were set to 2 times the reference values shown in Table 2 .

Table 3. Posterior probability distribution information.

\begin{tabular}{|c|c|c|}
\hline$\pi(P)$ & Parameter & $\begin{array}{c}\text { Estimative } \\
\text { (mean/credibility interval) }\end{array}$ \\
\hline Uniform & $\mu_{\text {máx }}$ & $\begin{array}{c}0.1243 \\
(0.1138-0.1363)\end{array}$ \\
\hline Gaussian & $\mu_{\text {máx }}$ & $\begin{array}{c}0.1140 \\
(0.1055-0.1216)\end{array}$ \\
\hline $\begin{array}{c}\text { Log- } \\
\text { normal }\end{array}$ & $\mu_{\text {máx }}$ & $\begin{array}{c}0.1144 \\
(0.1116-0.1178)\end{array}$ \\
\hline Rayleigh & $\mu_{\text {máx }}$ & $\begin{array}{c}0.1044 \\
(0.0986-0.1112)\end{array}$ \\
\hline Uniform & $\mathrm{K}_{\mathrm{S}}$ & $\begin{array}{c}31.2247 \\
(24.7450-39.1138)\end{array}$ \\
\hline Gaussian & $\mathrm{K}_{\mathrm{S}}$ & $\begin{array}{c}23.5779 \\
(17.8892-28.3819)\end{array}$ \\
\hline $\begin{array}{c}\text { Log- } \\
\text { normal }\end{array}$ & $\mathrm{K}_{\mathrm{S}}$ & $\begin{array}{c}23.8156 \\
(22.2408-25.7249)\end{array}$ \\
\hline Rayleigh & $\mathrm{K}_{\mathrm{S}}$ & $\begin{array}{c}17.3013 \\
(13.6789-21.6429)\end{array}$ \\
\hline Uniform & $\mathrm{Y}_{\mathrm{X} / \mathrm{S}}$ & $\begin{array}{c}0.0243 \\
(0.0241-0.0246)\end{array}$ \\
\hline Gaussian & $\mathrm{Y}_{\mathrm{X} / \mathrm{S}}$ & $\begin{array}{c}0.0242 \\
(0.0240-0.0244)\end{array}$ \\
\hline $\begin{array}{c}\text { Log- } \\
\text { normal }\end{array}$ & $\mathrm{Y}_{\mathrm{X} / \mathrm{S}}$ & $\begin{array}{c}0.0242 \\
(0.0239-0.0244)\end{array}$ \\
\hline Rayleigh & $\mathrm{Y}_{\mathrm{X} / \mathrm{S}}$ & $\begin{array}{c}0.0241 \\
(0.0239-0.0243)\end{array}$ \\
\hline
\end{tabular}

It is observed that the three parameters presented satisfactory convergence and for a Gaussian priori, more burn-in states were necessary for the convergence of the chain for an equilibrium distribution, resulting in acceptance rates around 81\%, while for the Uniform, Log-normal and Rayleigh priori, the acceptance rates ranged around $17 \%, 72 \%$ and $65 \%$, respectively.

The acceptance rate is the ratio between the number of states accepted in the Metropolis-Hastings test and the total number of states. According to Albert (2009), for models with one or two parameters, acceptance rates up to $45 \%$ are ideal, being reduced to $25 \%$ for models with more parameters. Thus, one consequence of achieving low acceptance rates is to assume that the Markov chain remains in the same state for several iterations, on the other hand, for high acceptance rates, although the Markov chain needs fewer iterations to evolve convergence occurs slowly.

Analyzing the probability distributions used as a priori information, the obtained results show that the Log-normal distribution presented the best estimates, indicating that this is a good alternative to be implemented, considering that the most used are the Gaussian and Uniform distributions.

For comparison purposes, knowing that the Log-normal function was the priori probability distribution which presented the best estimates, for this specific case it was estimated the six parameters of the model and compared the fit between the simulated measurements and the data predicted by the models using three and six parameters, as shown in the Fig. 4.
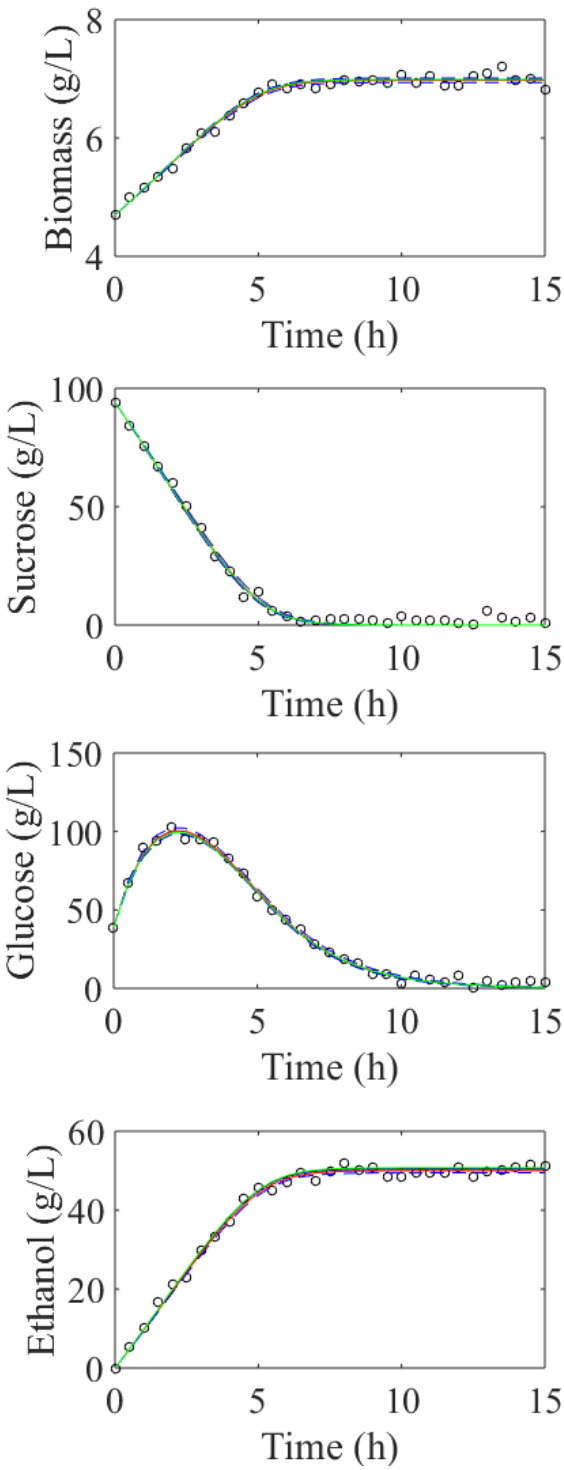

Figure 4. Model adjustment for the state variables, where three parameters (green), six parameters

(red), exact solution (black), simulated measurements (open circles) and credibility interval (blue).

The estimation of only three of the six model parameters leads to a satisfactory fit, with the advantage of time and computational cost reduced when compared to the estimation of the six parameters, confirming the importance of sensitivity analysis, especially in more complex cases where 
they employ models with a high amount of parameters.

\section{CONCLUSION}

The present work presented parameter estimation through the Monte Carlo Bayesian technique via Markov Chains, based on the verification of the Metropolis-Hastings algorithm, performing case studies evaluating the priori parameter information. Thus, it is concluded that the parameter sensitivity analysis of the proposed model to describe a physical phenomenon is of fundamental importance so that any difficulties in parameter estimation, high computational cost and high time demand are minimized.

The probability distribution used to represent the a priori information of the parameters is a key element in bayesian inference and, therefore it is essential that it be evaluated and specified from all available information, in order to avoid it does not represent well the parameter set of the model or even that a good fit of data occurs, but with parameters without scientific sense.

From the generation of simulated measurements under experimental uncertainty, the algorithm used was satisfactory in estimating the parameters of the model used, demonstrating the possibility of using it as a tool for cost reduction in experimental tests.

\section{REFERENCES}

Akgul, O., Zamboni, A., Bezzo, F., Shah, N., and Papageorgiou, L. G., 2010, Optimization-based Approaches for Bioethanol Supply Chains, Industrial \& Engineering Chemistry Research, Vol. 50, No. 9, pp. 4927-4938.

Albert, J., 2009, Bayesian Computation with R, Springer Science \& Business Media.

Beck, J. V., Blackwell, B., and Clair Jr., C. R., 1985, Inverse Heat Conduction: Ill-Posed Problems, James Beck.

Beck, J. V., 1979, Criteria for Comparison of Methods of Solution of the Inverse Heat Conduction Problem, Nuclear Engineering and Design, Vol. 53, No. 1, pp. 11-22.

Beck, J. V., and Arnold, K. J., 1977, Parameter Estimation in Engineering and Science, James Beck.

Corsano, G., Vecchietti, A. R., and Montagna, J. M., 2011, Optimal Design for Sustainable Bioethanol Supply Chain Considering Detailed Plant Performance Model, Computers \& Chemical Engineering, Vol. 35, No. 8, pp. 1384-1398.

Ehlers, R. S., 2011, Inferência Bayesiana, Departamento de Matemática Aplicada e Estat1stica, ICMC-USP. (in Portuguese)

Gamerman, D., and Lopes, H. F., 2006, Markov Chain Monte Carlo: Stochastic Simulation for
Bayesian Inference, Chapman and Hall/CRC.

Gamerman, D., and Migon, H. S., 1993, Inferência Estatística: Uma Abordagem Integrada, Rio de Janeiro, Instituto de Matemática - UFRJ. (in Portuguese)

Gelfand, A. E., and Smith, A. F. M., 1990, Sampling-based Approaches to Calculating Marginal Densities, Journal of the American Statistical Association, Vol. 85, No. 410, pp. 398-409.

Geman, S., and Geman, D., 1984, Stochastic Relaxation, Gibbs Distributions and the Bayesian Restoration of Images, IEEE Transactions on Pattern Analysis and Machine Intelligence, No. 6, pp. 721741.

Geweke, J., 1994, Bayesian Comparison of Econometric Models, Working Paper, Federal Reserve Bank of Minneapolis, Minnesota.

Gnansounou, E., and Dauriat, A., 2005, Ethanol Fuel from Biomass: a Review, Journal of Scientific and Industrial Research, Vol. 64, pp. 809-821.

Goldemberg, J., Coelho, S. T., Nastari, P. M., and Lucon, O., 2004, Ethanol Learning Curve - The Brazilian Experience, Biomass and Bioenergy, Vol. 26, No. 3, pp. 301-304.

Hastings, W. K., 1970, Monte Carlo Sampling Methods Using Markov Chains and their Applications, Biometrika, Vol. 57, No. 1, pp. 97-109.

Heidelberger, P., and Welch, P. D., 1983, Simulation Run Length Control in the Presence of an Initial Transient, Operations Research, Vol. 31, No. 6, pp. 1109-1144.

Kaipio, J. P., and Somersalo, E., 2004, Computational and Statistical Methods for Inverse Problems, Applied Mathematical Sciences, Vol. 160.

Lee, P., 2004, Bayesian Statistics, Oxford University Press.

Metropolis, N., and Ulam, S., 1949, The Monte Carlo Method, Journal of the American Statistical Association, Vol. 44, No. 247, pp. 335-341.

Naveira Cotta, C. P., 2009, Problemas Inversos de Condução de Calor em Meios Heterogêneos: Análise Teórico-Experimental via Transformação Integral, Inferência Bayesiana e Termografia Por Infravermelho, Doctoral Thesis, Universidade Federal do Rio de Janeiro, Rio de Janeiro, RJ. (in Portuguese)

Nitsos, C. K., Matis, K. A., and Triantafyllidis, K. S., 2013, Optimization of Hydrothermal Pretreatment of Lignocellulosic Biomass in the Bioethanol Production Process, ChemSusChem, Vol. 6, No. 1, pp. 110-122.

Özisik, M. N., and Orlande, H. R. B., 2000, Inverse Heat Transfer, New York: Taylor \& Francis.

Raftery, A. E., and Lewis, S., 1991, How Many 
Iterations in the Gibbs Sampler?, Washington Univ. Seattle Dept. Of Statistics.

Resende, M. D. V., 1999, Predição de Valores

Genéticos, Componentes de Variância, Delineamentos de Cruzamento e Estrutura de Populações no Melhoramento Florestal, Doctoral Thesis, Universidade Federal do Paraná, Curitiba, PR. (in Portuguese)

Rivera, E. C., Costa, A. C., Atala, D. I., Maugeri, F., Maciel, M. R. W., and Maciel Filho, R., 2006, Evaluation of Optimization Techniques for Parameter Estimation: application to Ethanol Fermentation Considering the Effect of Temperature, Process Biochemistry, Vol. 41, No. 7, pp. 1682-1687.

Silva, C. L., Santana, P. L., Silva, C. F., and Pagano, R. L., 2016, Modelagem e Estimação de Parâmetros do Processo de Produção de Etanol em Reator Batelada por Saccharomyces cerevisiae, Scientia Plena, Vol. 12, No. 5. (in Portuguese) 